\title{
Community-Engaged Faculty: A Must for Preparing Impactful Ed.D. Graduates
}

\author{
Deborah Peterson, Jill Alexa Perry, Lina Dostilio and Debby Zambo
}

\begin{abstract}
Since its inception nine years ago, CPED members have re-envisioned and implemented a new purpose for the professional practice doctorate in education, or Ed.D. This new purpose is grounded in the goal of preparing doctoral students to serve as scholarly practitioners, those who engage community as stakeholders in the process of improving problems of practice. Forming practitioners to be leaders in their communities under the CPED framework requires faculty who look beyond traditional roles by embEd.D.ing themselves in communities to work alongside practitioners working to transform their communities. Unfortunately, at many institutions, community-engagement is considered counternormative to the traditional interpretation of research, teaching, and service, though it need not be. This paper will discuss the implications of CPED's community-engagement principle for Ed.D. programs, institutional policies, and academic environments in which community-engaged faculty do their work and the importance of these faculty members in the design of the Education Doctorate.
\end{abstract}

\section{Introduction}

The Carnegie Project on the Education Doctorate consists of 80+ schools and colleges of education in the United States, Canada and New Zealand working in collaboration to improve the design of professional preparation programs at the doctoral level. Since its inception nine years ago, CPED members have reenvisioned and implemented a new purpose for the professional practice doctorate in education, the Ed.D. This new purpose is grounded in the goal of preparing educators to be scholarly practitioners, those who "blend practical wisdom with professional skills and knowledge to name, frame, and solve problems of practice... by collaborating with key stakeholders, including the university, the educational institution, the community, and individuals" (CPED, 2010). To develop Ed.D. programs like these across varied contexts, CPED offers a framework rather than a prescriptive program model. As its foundation, this framework presents a set of guiding principles, which stress the importance of preparing practitioners to be leaders in their communities and a set of design concepts that stress the importance of practicing the skills of a scholarly practitioner.

Forming practitioners to be leaders in their communities under the CPED framework requires intentionality in program design. This intentionality comes from faculty members who look beyond tradition and believe in the value of community-oriented scholarship as core to their workload. These faculty members understand the purpose of an Ed.D. degree, and in turn recognize that they themselves must be engaged in the community. As such, they work collaboratively in neighborhoods, schools, and organizations surrounding their institutions. They honor the strengths and recognize the challenges of community members and work with them to create positive change in mutually respectful ways. Such community-embedded faculty offer themselves as models for Ed.D. candidates as they contribute to coconstructed systems that respond to educational issues. Their research agenda is theoretical and practical. Their publications include scholarly and practitioner audiences. Their work meets rigorous standards and is to be commended on many levels.

However, as faculty have moved their research and scholarship into communities, promotion and tenure practices remain focused on tradition and review committees do not know how to appropriately value this 
type of work. Community-engaged scholarship introduces an orientation that challenges epistemological norms, as well as customs that govern who is considered to be an expert peer and what products of dissemination are considered rigorous. Perhaps the starkest misunderstanding of community-engaged scholarship is that it is merely service and supplementary to one's teaching and research, instead of being understood as a publicly-oriented reframing of academic work that is integrative of teaching, research, and service (Colbeck \& Wharton-Michael, 2006). Such an integrative and publicly oriented mode of scholarship presents "second order issues" that challenge the academy's norms and practices (Sandmann, Saltmarsh \& O'Meara, 2008, p. 50). Given the emphasis CPED places on practical redress of problems of educational practice, it is critical that colleges of Education that house CPED programs support faculty and students as they construct agendas of community-engaged scholarship and identities as communityengaged intellectuals.

In this paper, we will discuss the importance of community-engaged faculty in the design of the Education Doctorate under the CPED framework. Using data gathered from CPED consortium members, we first offer a glimpse as to how faculty are designing programs around community and offer insight as to the type of faculty needed to do this work. We then provide, as an example, the experiences of one such faculty member who has been enmeshed in community-engaged scholarship. She will describe her experience in developing community connections for her Ed.D. program and the challenges she has faced in the promotion and tenure process as a result. The paper concludes with a discussion on the ways in which universities could and should better value this work and support such faculty.

\section{The CPED Framework}

Within the initial years of the Carnegie Project on the Education Doctorate, faculty members rejected the idea of a one-size fits all program model. Members claimed that professionals entering doctoral programs came with varying needs that reflected their varying practitioner contexts--rural, urban, suburban PK-20 educational settings. Additionally, members argued that each university campus was unique which may or may not limit what could or couldn't be changed programmatically. Such variety and uniqueness across educational contexts, they argued, would not support a prescriptive model for the professional practice doctorate in education. Thus, members set out to define other ways to collectively improve the Ed.D. while honoring local contexts.

The answer began with a new definition of the Ed.D. that members characterized as: "The professional doctorate in education prepares educators for the application of appropriate and specific practices, the generation of new knowledge, and for the stewardship of the profession" (CPED, 2009). With this understanding, members developed a framework upon which programs could apply this definition to their local context to design the strongest professional preparation possible. This framework consists of a foundation of six program design principles, a set of design-concepts that support the building of programs, and four overarching constructs that have been investigated to understand how programs have operationalize this framework. The program design principles state that the Professional Doctorate in Education:

1. Is framed around questions of equity, ethics, and social justice to bring about solutions to complex problems of practice.

2. Prepares leaders who can construct and apply knowledge to make a positive difference in the lives of individuals, families, organizations, and communities.

3. Provides opportunities for candidates to develop and demonstrate collaboration and communication skills to work with diverse communities and to build partnerships.

4. Provides field-based opportunities to analyze problems of practice and use multiple frames to develop meaningful solutions. 
5. Is grounded in and develops a professional knowledge base that integrates both practical and research knowledge, that links theory with systemic and systematic inquiry.

6. Emphasizes the generation, transformation, and use of professional knowledge and practice (CPED, 2009).

The design-concepts include signature pedagogy, laboratory of practice, inquiry as practice, problem of practice, dissertation in practice and scholarly practitioner. Definitions for these concepts can be found on the CPED website (http://cpedinitiative.org). For the purposes of this paper, we offer the definitions of only two of the design-concepts - scholarly practitioner and laboratory of practice - before discussing how member programs have operationalized this framework as a means to promote community engagement in Ed.D. programs.

Scholarly Practitioner was admittedly one of the last of the CPED design-concepts to be defined, namely because it was meant to represent the culmination of the Ed.D. program. According to CPED, a scholarly practitioner is one who:

blends practical wisdom with professional skills and knowledge to name, frame, and solve problems of practice; uses practical research and applied theories as tools for change because they understand the importance of equity and social justice; disseminates their work in multiple ways; and has an obligation to resolve problems of practice by collaborating with key stakeholders, including the university, the educational institution, the community, and individuals (CPED, 2010).

This definition represents the graduate who has been formed through a CPED-influenced Ed.D. program and exemplifies the CPED definition of the Ed.D.

While all of the CPED design-concepts contribute to the formation of the scholarly practitioner, the laboratory of practice in particular relates to the ways in which community engagement is learned and how principle \#3 (Provides opportunities for candidates to develop and demonstrate collaboration and communication skills to work with diverse communities and to build partnerships) is enacted in CPEDinfluenced Ed.D. programs. Therefore, the laboratory of practice for professional preparation is:

a setting where theory and practice inform and enrich each other. They address complex problems of practice where ideas - formed by the intersection of theory, inquiry, and practice — can be implemented, measured, and analyzed for the impact made. Laboratories of Practice facilitate transformative and generative learning that is measured by the development of scholarly expertise and implementation of practice (CPED, 2010).

This CPED design-concept moves away from the traditional critique of laboratories-wherein academics carry out experiments in communities - towards a new definition that advocates collaborative spaces that facilitate transformative and generative learning. In this sense, the practitioner works with coalitions of stakeholders (that include academics, students, educators, community leaders, residents, etc.) to create opportunities to dream innovatively together and to develop promising strategies to address local problems.

Over the past nine years, the CPED framework has been adopted by all member institutions (originally 25 , now over 80 ) as well as by a significant number of non-member institutions. The underlying commitment to this framework is the belief that scholarly practitioners can and must transform their own practices. Such growth both within and outside of the CPED organization indicates strong interest among institutions of higher education to respond to the needs of educational practitioners. The result has been 
the creation of Ed.D. programs that empower these leaders to transform educational systems and better lead those that work on the front lines of education (Perry, Zambo, \& Wunder, in press).

\section{CPED \& Community Engagement}

As we have noted above, the importance of community connections and partnerships are noted in CPED's third principle and in its definitions of scholarly practitioner and laboratory of practice. Like other aspects of the CPED framework, the consortium is continually working to better understand if, and how, this principle and these design-concepts are being enacted in member Ed.D. programs. When asked how this should be performed, consortium members noted that a set of "constructs" could be used to look across the CPED framework, allowing for the many aspects to weave together. Given this, a team of Improvement Fellows (faculty from CPED member institutions) were invited to join in CPED research efforts and tasked with defining these constructs and gathering data across the consortium. One construct noted to be important was the role of community connections and partnerships. To investigate this construct Fellows operationally defined it as: "community connections and partnerships require consistent, persistent, and equally honored engagement between and mutually beneficial outcomes for academicians and stakeholders in and from the community" (CPED, 2015). Using this definition data were gathered from CPED members in June 2015.

Several findings emerged that have helped CPED understand its members' work with community in Ed.D. programs and the importance of supporting faculty as they create and foster community practice contexts for the formation of scholar practitioners. The role of community connections and partnerships, the CPED Fellow's found, serves different purposes in member Ed.D. programs and at different stages Ed.D. program development. With an initial survey, it was discovered that the notion of community connections and partnerships provided structure for the overall Ed.D. program design as well as in the selection of scholarly literature and assignments that Ed.D. students complete.

Program structures tended to come from theoretical frameworks that focus on culture, place, social action, collaboration, and criticality. Students learn about critical reflection, democratic ideals, and the socio-cultural context of schooling and learning by reading literature focused on community and education (e.g., curriculum, pedagogy, and context) and the influence of race, gender, and class on educational opportunities. Assignments are active, applied, and aimed at helping students research their actions and ideas. Ed.D. students are typically asked to build partnerships in varied communities and to conduct action-oriented studies that collect data, perform analysis, and present findings in co-constructed ways. Through data CPED learned that enacting the CPED framework in an Ed.D. program made community connections and partnerships an integral part of professional preparation. Ed.D. students are being exposed to intentional program designs that offer scholarship and experiences focused on community engagement. As a result, these students become action-oriented, reflective scholar practitioners.

Wanting to delve deeper, Fellows collected more data at one of its bi-annual meetings. Focus groups were formed with approximately 150 faculty members who were working at varying stages of designing and implementing their programs. Fellows asked members to explain how their programs defined community connections and partnerships and what these definitions looked like in their Ed.D. programs. Data from these sessions showed that faculty in the early phases of designing their programs stressed the importance and role of community connections and partnerships in all aspects of program design. These faculty were largely optimistic that embedding their students in communities would both benefit and challenge thinking, and teach students to co-construct community based research. Faculty members in this design stage saw the ultimate goal of community work as developing leaders who learn from and with varied communities and in turn, take back what they learn in their courses to their own communities. 
Along the same lines, faculty members who were in the process of implementing their CPED-influenced Ed.D. program believed that community connections would challenge student thinking. However, with a bit of programmatic experience under their belts, these faculty members questioned the "hows" of doing this work. In particular, faculty struggled with the "boundaries" that defined community. For example, they asked 'is community broadly defined to mean the state or regional levels, or should it be more narrowly defined such as the individual student's' work site?' In addition, this group of faculty participants grappled with the notion of what it meant to 'know one's community and work effectively in one's community.'

In contrast, faculty members whose programs were established and had graduated students viewed community engagement in Ed.D. programs as variable. This meant building community within the programs themselves by inviting diverse individuals from varied contexts (K-12 teachers, administrators, higher education, organization leaders, etc.), or engaging community-stakeholders into the admissions process by asking applicants to supply reference letters from these individuals. Community and partnerships were also part of the ethos of their programs and threaded throughout the curriculum as students worked on problems of practice found in communities and worked on dissertations in practice that impacted communities (see CPED website for this design-concept definition). However, these faculty members noted challenges in utilizing community connections and partnerships during the dissertation process.

What these data highlight is that faculty members believe community engagement has an important role in professional preparation programs in education. However, it also notes the complexity faculty face in designing these connections and experiences for their students and themselves. In the next section, we supply a framework for this work and then outline ways in which faculty have been successful in integrating community engagement into CPED-influenced Ed.D. programs by offering the experience of one CPED faculty member. We will then discuss the characteristics of these individuals and the need and ways for making their work easier through a university-wide support system.

\section{The Tempered Radical}

Leading the redesign of a CPED-influenced Ed.D. is not always an easy endeavor for the faculty member who finds him/herself battling policy, procedures and colleagues that are steeped in traditional academic culture (Perry, 2013). Additionally, these faculty members face personal consequence because traditional faculty reward structures do not incorporate informal efforts (O'Meara, 2006) such as redesigning programs. Despite these challenges, however, many assistant and associate faculty members around the country have persisted creating Ed.D. programs that are innovative and non-traditional. Perry (2010, 2013) found that these faculty members who lead changes in Ed.D. program designs were often successful because they exhibit qualities of "tempered radicals."

Meyerson's (2003) Tempered Radicals Framework describes individuals who both identify with and are committed to their institutions but who are also committed to a cause or movement that is "fundamentally different from and possibly at odds with the dominant culture of their organization" (Meyerson \& Scully, 1995, p. 186). These leaders aspire to create positive change but have no formal authority. As a means to limit personal discomfort in moving the agenda forward, they must temper or tailor their strategies. Tempered radicals rely on a variety of strategies that do not necessarily follow a formal step-by-step process, but rather offer ways to tackle obstacles and resistance. Meyerson's model identified the difficulties that faculty members face during the change process and described them at various levelsthe individual or psychological level (motivation, identity, and resilience), the group or social psychological level (strategy, tactics, power dynamics), and the organizational level (leadership development, group formation, structure and culture). 
The Tempered Radical Framework offers a lens through which to understand how one faculty member at a CPED-influenced Ed.D. program created an Ed.D. program focused on community engagement despite institutional and personal challenge. In the next section, we offer the story of Deborah.

\section{Deborah's Story}

Clinging to traditional concepts regarding the doctorate in education as well as traditional faculty expectations for teaching, research, and service in CPED-influenced institutions may result in the decrease of higher education's relevance in educational reform. To remain relevant, institutions must provide meaningful Ed.D. programs for practitioners. CPED's framework provides clear guidance for transforming the focus and the pedagogy of the Ed.D., as envisioned by Shulman, Golde, Bueschel, and Garabedian (2006) and Perry and Imig (2008) to ensure our Ed.D. graduates can transform our PK-20 school systems. Furthermore, institutions of higher education can remain relevant by supporting faculty who align their research, teaching, and service with the CPED framework. This means supporting faculty who are doing innovative work and clarifying promotion and tenure expectations for community-engaged scholars who work in communities and in practice settings.

My identity as a community-engaged scholar was informed by 30 years as a teacher and school administrator. I intended to return to a school leadership position after completing my dissertation and serving as part-time clinical faculty preparing future school leaders. Instead, I accepted a tenure-line position within an institution known for its innovation and community engagement, Portland State University. My appointment letter included the traditional expectations in the areas of teaching, research, and service. While our promotion and tenure policies include traditional evaluation concepts such as "quality," "impact," and "peers," many within our university are working to ensure that faculty contributions are evaluated in ways that are inclusive (Ellison \& Eatman, 2008), reflect CPED principles, and integrate an expanded understanding of community-engaged scholarship.

While I had considerable expertise and success serving as a scholarly practitioner leading schools and as a clinical faculty member, my transition to a community-engaged, tenure-line scholar was challenging. However, several important factors eased the transition in several ways. My program coordinator, department chair, research director, and dean provided substantial support for my transition: release time to engage partners, funds to develop my scholarly agenda, professional development at national conferences on educational inequities, regular meetings with the associate dean, and graduate assistant time to support community outreach. These resources ensured my work was embedded in the community, of support to those seeking to end educational disparities, and would also contribute to our graduate school and university's mission of serving our community within the promotion and tenure focus on teaching, research, and service.

My transition to a community-engaged scholar was also eased by my assignment to teach in the administrator licensure program and the educational administration doctoral program. As a part of teaching in the doctoral program, I conducted research with one of my students who is Latino, a leader in the state Latino advocacy organization, and a mentor in the Latino mentoring program. We completed all aspects of one study side by side, examining the experience of 10 award-winning Latino administrators in the Pacific Northwest. We presented our results to the Latino mentoring program participants, and a research article has been accepted for publication in a scholarly journal. This work addressed all six CPED principles, generated new professional knowledge, and was transformative in nature, not just for my doctoral student, but also for our respective educational organizations, for future school leaders, and for me as a community-engaged scholar. This student's doctoral cohort recently asked if we could further investigate the findings by conducting an additional study in the coming year, applying the concepts they are learning in their doctoral research sequence to this next study. 
My transition to community-engaged scholar conducting research was eased by my deep connections within the local educational community, which increased my opportunity to collaborate on research of importance to the community. Two additional research opportunities emerged: one researching a program I developed while a high school administrator and the other collaborating with a school district on a culturally responsive teacher evaluation rubric.

When I served as a high school principal, several well-connected business people asked me to identify the most pressing problem that I faced in my role. I shared with them the complexity of teaching 200 students who were homeless, struggling to pay for rent or electricity in whatever way possible (Peterson \& Lehnhoff, 2013). The business group subsequently helped secure a $\$ 160,000$ grant to provide social services coordination in the school. As a community-engaged scholar, the same group asked me to conduct a study on the impact of that model on the students' abilities to graduate from high school. I was able to locate students who became the subjects in the study. When the study was completed, I wrote a White Paper. The paper presented the data from the now-graduated students on which aspects of the school-based social services coordination helped them graduate. I also created an implementation model and budget for school-based social services. A recommendation for statewide policy changes was included in the paper. My colleague and I shared the plan with three of the highest elected and appointed officials at the state and county level as well as those leading after-school programming and health and human services in our state. We met with the leaders of a major education advocacy organization and the chair of the city's policy group on high school completion. After 18 meetings over the course of 6 months, and securing funding commitments from existing county and state resources, our model was adopted 11 months after my study began by an education advocacy organization. That organization oversaw implementation of the plan 7 months later, impacting hundreds of students in six of the highest poverty high schools in our county.

My research developing a culturally responsive teaching rubric also began through ties I had as a scholarly practitioner. An ESL director with whom I had worked as a principal, contacted me in my role as assistant professor to ask if I would join the district's Native Cultural Trust and collaborate in writing a grant to develop and implement a rubric that examined teaching from the indigenous perspective. After receiving the grant, I built on the work of Julie Cajune, the Montana Indian Education program, and Geneva Gay to create an initial draft of a rubric. The school district's Title vii Coordinator facilitated the Native Cultural Trust's work as they revised and implemented the rubric over a two-year period. The teachers in her district use the rubric to evaluate their lessons. My administrative licensure students implement the rubric in their assignments related to instructional leadership and culturally responsive teaching. As a result of our collaboration, the district has created resources for those teachers who are expanding their understanding of culturally responsive instruction specific to Native youth, and 45 future school leaders have an additional tool for providing feedback to teachers. I am now collaborating with an internationally recognized scholar of Indigenous teaching praxis and the school district's Title vii coordinator to publish this work in practitioner and scholarly journals.

Service to my institution began as a first-year tenure-line faculty member when I was appointed to represent our department as a member of the Doctoral Program Council. Soon thereafter, I was tasked with revising the education administration doctoral specialization to reflect CPED principles and to ensure alignment with other doctoral specializations in our department. Despite years of leadership experience in schools and a firm knowledge of change leadership literature, leading this change effort was challenging. I was the least senior faculty member in our specialization. The expected timeline for completion of the redesign was at a pace faster than was comfortable for my more experienced colleagues. CPED principles had been embraced by our faculty but were not yet operationalized in terms of admissions, curriculum, or program outcomes. Leading the process of meeting with tenured faculty who had previously taught doctoral courses and redesigning their syllabi based on CPED principles was 
nothing short of terrifying. I did not have the positional authority to lead this process. However, a twoyear effort resulted in the redesign of our Ed.D. with the unanimous approval of all department faculty and Doctoral Program Council members. Our redesigned specialization reflected a strong focus on leadership for equity and an expectation that our doctoral students focus on community-engaged scholarship. Articulating the quality and impact of this work for my promotion and tenure portfolio has been challenging.

Perhaps I am an example of what Perry (2013) explicates in her examination of "tempered radicals" (Kezar \& Lester, 2011). I am deeply committed to my institution; yet I am equally committed to preparing fierce equity leaders who will eliminate educational disparities in our schools in their various leadership roles. I want to impact the preparation of current practitioners as well as contribute to the knowledge base of what works to reduce educational disparities. Articulating how my work provides a bridge between the world of scholarly practitioners and academics, a focus that I am committed to while following the traditional format outlined in promotion and tenure articles has resulted in me articulating my work as follows:

Research. In the past year, I have had two articles accepted for publication in peer-reviewed journals, one abstract accepted for development into an article in a peer-reviewed journal and one non-refereed contribution to a book chapter. Since my appointment in 2011, I have published six peer-reviewed articles, three refereed chapters in conference proceedings, and three non-refereed publications.

State and National (Refereed) Presentations. In the past year, I have given four refereed presentations. Since my appointment in 2011, I have given 15 refereed presentations on various aspects of school leadership for equity; I am developing these presentations into scholarly or practitioner articles for peer-reviewed journals.

Local and State (Invited) Presentations. I have given six invited presentations in the past year, a total of 14 since appointment in 2011. All presentations focused on leadership for equity. (cite from Peterson, personal narrative.)

However, as Ellison and Eatman (2008) note, the work of community-engaged scholars does not necessarily fall neatly into one discrete category of teaching, research, or service. Boyer (1990) first proposed and Ellison and Eatman later expanded upon the concept of a continuum, a framework for making sense of the work of faculty who are transforming their institutions and communities through community-engaged scholarship. It is also important for deans, provosts, and promotion and tenure committees to understand the community-engaged scholarship continuum when evaluating promotion and tenure portfolios of community-engaged scholars. For example, traditional definitions of "impact" and "peers" are not necessarily the same for community-engaged scholars as they are for traditional scholars. In my case, while many of my colleagues celebrated the impact of an article published in Educational Leadership, a practitioner journal distributed to 160,000 educational leaders, other more traditional colleagues discounted its value based on their interpretation of "peers" as fellow academicians and "impact" based on citations or other traditional, academic metrics. Similarly, while some colleagues recognized the impact of my work to embed social workers in schools, others evaluate this contribution as service.

I am sure there will be those who believe it is my inexperience that leads me to focus my energies on the community-engaged scholarship that I have described above. Antonio, Astin and Cress (2000) note that women and faculty of color are more likely to value community-engaged scholarship and that while this focus may limit their academic promotions, they are unwilling to engage in anything other than community-engaged scholarship. This is how I am oriented to my work. I want to impact current 
practitioners who can immediately reduce educational disparities in their roles as doctoral students and as school leaders. Simultaneously, I want to contribute to the research base on characteristics of leaders reducing educational disparities. I know that while the academy is in the process of transitioning to a broader, more inclusive and socially just orientation toward community-engaged scholarship, there are some who will prefer traditional epistemologies and frameworks. I believe it is with care for my professional future that members of the promotion and tenure committee and some mentors encourage me to only engage in activities that demonstrate traditional interpretations of scholarly production. Their guidance is offered as genuine support. I value their wisdom and care. And yet the "tempered radical" in me, the part of me that nudges against boundaries from within my organization to transform it, our students, and our communities to create a more socially just world, also believes in the power of our faculty and institutions to change.

As I continue my focus preparing school leaders to be fierce leaders for equity, I have found support from colleagues within our institution and in professional organizations. While the promotion and tenure committee advised me to submit a traditional narrative and engage only in data-driven research (rather than conceptual explorations) and publish only in traditionally defined peer-reviewed journals, the committee also recognized the impact of my leadership on community-based organizations. Tenured professors within my institution and from other CPED-inspired institutions have reached out to mentor me on navigating traditional promotion and tenure expectations during our institution's transition to honoring community-engaged scholarship and the expanded definition of "peers" for those transforming educational organizations as part of their scholarship. President Emerita Ramaley, one of our institution's key leaders in community-engaged scholarship, mentored me through the yearlong Portland State University Office of Global Diversity and Inclusion mentoring program. A CPED Improvement Fellow offered to examine my portfolio through the critical lens of an outside reviewer nine months before its due date to ensure I've clearly articulated my case to potential reviewers who are new to the concepts of community-engaged scholarship. Colleagues teaching in the doctoral program asked to meet with me to explore what it means to teach in a CPED-influenced doctoral program and what the implications are for their pedagogy and learning outcomes. After I presented on the Ed.D. change process at a recent CPED convening, several colleagues reached out to ask for more strategies on leading the change process in their institutions. The colleagues described above are not content to cling to traditional concepts regarding Ed.D. programs or faculty promotion and tenure expectations; rather they are supporting others while also transforming their own practices, programs, and institutions.

\section{Characteristics and Contexts that Support Community-Engaged Scholarship}

One might ask where CPED doctoral students come into this argument. After all, CPED is most centrally concerned with revolutionizing the preparation of educational leaders such that they are scholarly practitioners, able to effect change within their practice contexts and to respond to the educational inequities facing our world today. Quite simply, socialization and adequate learning experiences are necessary for us to reach these goals. CPED doctoral students must be socialized to value communityengaged scholarship and given the experiences and learning opportunities to effectively engage with others across institutional and sector boundaries. According to O'Meara (2011, p. 186):

If graduate students do not have an apprenticeship of sorts in [community] engagement (Golde, 2008) and if they do not develop professional identity as [community] engaged scholars (Colbeck, 2008), they will not develop the knowledge, skills, and professional orientation (Austin $\&$ McDaniels, 2006) to truly become [community] engaged scholars (O’Meara, 2008c).

The ability to provide such an experience through a laboratory of practice is directly determined by the capability of CPED faculty members to offer such learning. To do this authentically, we assert, would 
require that CPED faculty member adopt community-engaged scholarship themselves. Two key factors affect this possibility — individual characteristics and institutional context.

First, a faculty member's motivation to do community-engaged scholarship is not only influenced by the institutional context in which they work (Colbeck \& Wharton-Michael, 2006); personal characteristics and dispositions also strongly influence a desire to do community-engaged scholarship. As our colleague Deborah relates above, her motivation for stepping out of the public education sector and into the academy stems from a transformation agenda. She selected the environment she felt best positioned her to more powerfully enact educational change - the academy. Her ability to foster this work in an academic setting stems from her collaborative nature, which resonates with a democratic epistemology (Saltmarsh, Hartley \& Clayton, 2009).

Other characteristics that may contribute to one's community-engaged orientation include gender (which Deborah exemplifies) and race. Women are more likely to involve their students in community-based learning (Antonio, Astin \& Cress, 2000) at the university-level. Faculty of color, on the other hand, are more likely to be involved in outreach and to support university students who undertake outreach (O'Meara, 2002). As a result of these characteristics, women and faculty of color are overrepresented among those who undertake community-engaged scholarship (Vogelgesang, Denson, \& Jayakumar, 2010) within academia. Thus, if CPED member institutions seek to attract a vibrant, diverse faculty who are eager to undertake transformational agendas, making a pathway that supports community engagement is essential. Changing the structures that typically hinder such faculty work is a necessary step.

Second, faculty that do community-engaged scholarship need an institutional context that supports such research not only at the policy level but also at the personal level. In their work on faculty motivation for public scholarship, Colbeck \& Wharton-Michael (2006) assert that a faculty person's context beliefswhen one expects the institution will support their goal attainment - are influenced by the degree they believe senior faculty will understand and value their community-engaged scholarship. Many other studies centralize the influence of the institution on whether or not faculty will adopt or persist in their use of community-engaged scholarship (for example, Beere, Votruba \& Wells, 2011; Jaeger, Jamison, Clayton, 2012; O'Meara 2005; Sandmann and Weerts 2008). Therefore, to fully realize the role of community-engagement CPED-influenced Ed.D. programs, it is not sufficient enough to attract new faculty such as Deborah. We must be prepared to receive and retain these faculty, having familiarity and experience with community-engaged scholarship throughout our ranks as well as having policies and processes that promote the legitimacy and rigor of community-engaged scholarship. Sandmann, Saltmarsh, and O'Meara (2008) stress the importance of moving community-engagement scholarship into the core of institutional practice. To do this, they note, "It will have to be advanced at the level of secondorder changes - changes that move beyond programs, structures, and rhetorical positioning to involve institutional culture and underlying policy. Second-order changes are significantly more difficult to enact and require sustained effort over longer periods of time" (p. 50).

\section{Implementing Practices Conducive to Community Engagement}

As a result of its work CPED is changing institutional structures to foster innovation. In the context of community engagement, CPED is undertaking this challenge alongside American higher education and the multitude of disciplinary associations have been wrestling with how to best advance communityengaged scholarship for some decades now. Sandmann, Saltmarsh and O'Meara (2008) assessed the effectiveness of strategies that have been used to advance community-engaged scholarship, which range from redefining how a faculty members approach and characterize their work, to revising tenure and promotion guidelines, to assisting faculty to emphasize the rigor and quality of their community-engaged scholarship, to establishing a national pool of community-oriented peer experts who could review and evaluate community-engaged scholarship, to combining all of these approaches within a disciplinary 
stream such as the health sciences (through the work of Community-Campus Partnerships for Health). All told, the authors found these strategies to be lacking. Rather, they propose a new model for communityengaged scholarship that integrates change within four university homes: within graduate education, the departmental unit, disciplinary associations, and the institution as a whole.

Their model intersects faculty socialization and institutional change as a means to advance communityengaged scholarship. With regard to socialization, this occurs in graduate programs as they prepare graduate students equipped to undertake community-engaged scholarship as well as in the disciplinary homes of faculty as disciplinary associations seed community-engaged scholarship through special interest groups, conference themes, and national calls for publicly-oriented forms of the discipline. With regard to institutional change, Sandmann, Saltmarsh, and O'Meara's (2008) model cites faculty development and support for engagement as necessary practices. Such support includes amending tenure and promotion awards for community engagement and helping faculty to document community engagement in their dossiers. However, the unique insight their model provides is to suggest that strong institutional change isn't simply dependent on implementing the aforementioned practices, but doing so in ways guided by change theory and in ways that integrate changes across multiple aspects of the institution.

CPED might well consider adopting this model for community-engaged scholarship as a compass for its efforts to collaborate with member institutions to facilitate CPED principle \#3. Focusing efforts across CPED member institutions to socialize their faculty toward community-engaged scholarship and to change the processes and policies that most affect community-engaged scholarship is a wise investment. Some examples of how the Sandmann, Saltmarsh, \& O'Meara (2008) model could be interpreted in the CPED context might include the following suggestions.

CPED's most direct influence could be exerted in the areas of:

- Influencing graduate education by building up the resources and understanding of a laboratory of practice such that it is consonant with the Carnegie definition of engagement and providing recognition or reward to those graduate students who are most visibly enacting CPED's commitments to community engagement). One idea might be to crystalize what a CPED graduate would look like in two areas: K-12 leadership and faculty (of course underscoring the community-engaged nature of these graduates) Also, for those CPED institutions who are preparing future faculty, they ought to leverage the AAC\&U Preparing Future Faculty work.

- Exerting influence as a kind of disciplinary association by utilizing CPED convenings, scholarly opportunities, and peer networks to advance scholarship and practice on community engagement in the CPED context and by developing resources that support the appropriate evaluation of community-engaged scholarship conducted by CPED faculty. This latter task could be modeled after the work has been done by Community Campus Partnerships for Health.

- Encouraging CPED institutions to create change at the departmental level by creating models of portfolio development that portrays how one's community-engaged scholarship can be effectively positioned (whether or not the indicators for reward explicitly name and/or characterize) community-engaged scholarship) to the best effect within the institution's existing promotion and tenure guidelines. Additionally, CPED influenced departments can harness models for development over time such as using tools like the Engaged Departments Rubric (Kecskes, 2008). CPED may be able to model this departmentally-located work by providing opportunities within convening structures for CPED schools to showcase their dossier work and use of the Engaged Departments rubric to create departmental policies and practices more conducive community-engaged scholarship. 


\section{Conclusion}

If schools of education want to remain relevant, then these institutions must find better ways to prepare those leaders who are struggling to improve our nation's PK-20 education systems. The CPED framework for redesigning Ed.D. programs is one very real way to do this. However, if we are to expect that educational practitioners who graduate from CPED-influenced Ed.D. programs will possess the skills, knowledge and dispositions to be scholarly practitioners then we must provide the laboratories that offer real practice for students to learn how to connect to communities and produce community-engaged research. Community-engaged faculty who teach in these programs are the key. Finding and supporting faculty who can establish strong community connections and incorporate those connections into their teaching and scholarship should be a high priority of both CPED and non-CPED member institutions. Looking to our colleagues who study community-engaged scholarship provides a solid start. 


\section{References}

Antonio, A. L., Astin, H. S., \& Cress, C. M. (2000). Community service in higher education: A look at the nation's faculty. Review of Higher Education 23 (4), 373-398. doi:

http://dx.doi.org/10.1353/rhe.2000.0015

Beere, C. A., Votruba, J. C., \& Wells, G. W. (2011). Becoming an engaged campus: A practical guide for institutionalizing public engagement. Hoboken, NJ: John Wiley \& Sons.

Carnegie Project on the Education Doctorate. (2010). CPED design concepts. College Park, MD: Author.

Carnegie Project on the Education Doctorate (2009). Working principles for the professional practice doctorate in education. College Park, MD: Author.

Colbeck, C. L., \& Wharton-Michael, P. (2006). Individual and organizational influences on faculty members' engagement in public scholarship. New Directions for Teaching and Learning 2006 (105), 1726. doi: http://dx.doi.org/10.1002/t1.221

Ellison, J., \& Eatman, T. K. (2008). Scholarship in public: Knowledge creation and tenure policy in the engaged university. Syracuse, NY: Imagining America.

Jaeger, A. J., Jameson, J. K., \& Clayton, P. (2012). Institutionalization of community-engaged scholarship at institutions that are both land grant and research universities. Journal of Higher Education Outreach and Engagement 16 (1), 149-170. doi: http://dx.doi.org/10.1287/orsc.6.5.585

Kecskes, K. (2008). Creating community-engaged departments: Self-assessment rubric for the institutionalization of community engagement in academic departments. Portland State University.

Meyerson, D.E. (2003). Tempered radicals: How everyday leaders inspire change at work. Boston: Harvard Business School Press.

Meyerson, D., \& Scully, M. (1995). Tempered radicalism and the politics of ambivalence and change. Organization Science 6 (5), 585-600. doi: http://dx.doi.org/10.1287/orsc.6.5.585

O'Connor, B., Anthony-Stevens, V., \& Gonzalez, N. (2014). Nurture and sustain a culture of collaboration, trust, learning, and high expectations. R. Ylimaki (ed.). The New Instructional Leadership: ISLLC Standard Two. New York: Routledge.

O'Meara, K. (2002). Uncovering the values in faculty evaluation of service as scholarship. Journal of Higher Education 26 (1), 57-80. doi: http://dx.doi.org/10.1353/rhe.2002.0028

O'Meara, K. A. (2005). Encouraging multiple forms of scholarship in faculty reward systems: Does it make a difference? Research in Higher Education 46 (5), 479-510. doi: http://dx.doi.org/10.1007/s11162$\underline{005-3362-6}$

O'Meara, K. (2011). Faculty civic engagement: New training, assumptions, and markets needed for the engaged American scholar. In J. Saltmarsh \& M. Hartley (Eds.) To serve a larger purpose: Engagement for democracy and the transformation of higher education (pp. 177-198). Philadelphia, PA: Temple University Press. 
O’Meara, K. \& Jaeger, A. (2006). Preparing future faculty for community engagement: Barriers, facilitators, models, and recommendations. Journal of Higher Education Outreach and Engagement 11 (4), 3-26.

Perry, J. A. (2010). Reclaiming the education doctorate: Three cases of processes and roles in institutional change (Doctoral dissertation). University of Maryland, College Park.

Perry, J.A., \& Imig, D.G. (2008 November/December). A stewardship of practice in education. Change 40 (6), 42-48. doi: http://dx.doi.org/10.3200/CHNG.40.6.42-49

Perry, J.A. (2014). Changing schools of education through grassroots faculty-led change. Innovation in Higher Education, 39 (2), 155-168. doi: http://dx.doi.org/10.1007/s10755-013-9267-y

Perry, J.A., Zambo, D. \& Wunder, S. (in press). Understanding how schools of education have redesigned the doctorate of education. Journal of School Public Relations 36, 58-85.

Saltmarsh, J., Hartley, M. \& Clayton, P.H. (2009). Democratic engagement white paper. Boston, MA: New England Resource Center for Higher Education.

Sandmann, L., Saltmarsh, J., \& O'Meara, K. (2008). An integrated model for advancing the scholarship of engagement: Creating academic homes for the engaged scholar. Journal of Higher Education Outreach and Engagement 12 (1), 47-64.

Shulman, L. S., Golde, C.M., Bueschel, A.C., \& Garabedian, K.J. (2006). Reclaiming education's doctorates: A critique and a proposal. Educational Researcher 35 (3), 25-32. doi: http://dx.doi.org/10.3102/0013189X035003025

Vogelgesang, L. J., Denson, N., \& Jayakumar, U. M. (2010). What determines faculty-engaged scholarship? The Review of Higher Education 33 (4), 437-472. doi: http://dx.doi.org/10.1353/rhe.0.0175

\section{Author Information}

Deborah Peterson prepares future school leaders with a strong focus on leadership for equity and reducing educational disparities as assistant professor in the Educational Leadership and Policy Department at Portland State University. Her research examines the experience of school leaders who successfully reduce educational disparities. She collaborates with community groups, school districts, and professional organizations to support context-specific solutions to problems of practice in schools.

Deborah Peterson, Ed.D.

Portland State University

Graduate School of Education

Educational Leadership and Policy

PO Box 751

615 SW Harrison

Room 506U

Portland, Oregon 97207-0751

Phone: 503-725-4688

Fax: 503-725-3200

Email: dpeterso@pdx.edu 
Jill Alexa Perry is the Executive Director of the Carnegie Project on the Education Doctorate (CPED) and a Research Associate Faculty member at the University of Pittsburgh. Dr. Perry's research focuses on professional doctoral preparation in education, organizational change in higher education, and faculty leadership in higher education. Dr. Perry received a Bachelor of Arts in Spanish and International Studies and a Masters of Arts in Higher Education Administration from Boston College. She holds Ph.D. in International Educational Policy from the University of Maryland. She is a Fulbright Scholar (Germany) and a returned US Peace Corps Volunteer (Paraguay).

Jill Alexa Perry, Ph.D.

University of Pittsburgh

4318 Wesley W. Posvar Hall

230 South Bouquet Street

Pittsburgh, PA 15260

Cell: 301-204-2644

Phone: 412-624-7272

Email: jperry@pitt.edu

Lina D. Dostilio directs the Center for Community-Engaged Teaching and Research at Duquesne University in Pennsylvania. In this capacity, she facilitates teaching and research collaborations that involve university stakeholders in public problem solving across an array of social and environmental issues. Lina previously served as Chair of the Board of Directors of the International Association for Research on Service-Learning and Community Engagement and is the Scholar in Residence for Campus Compact's Research Project on the Community Engagement Professional.

Lina D. Dostilio, Ed.D.

Duquesne University

A.J. Palumbo Center

600 Forbes Avenue

Pittsburgh, PA 15282

Phone: 412-302-4810

Email: dostilioL@duq.edu

Debby Zambo, Professor Emerita from Arizona State University is currently working as the Associate Director of the Carnegie Foundation on the Education Doctorate (CPED). While at ASU as Coordinator of the Ed.D. in Leadership and Innovation program while at ASU. Debby's research interests include newly designed Ed.D. programs and the application of educational psychology to educational practice. Since 2012 she has worked closely with Dr. Jill Perry, Director of CPED, helping with various aspects of the organization. In 2014 she became the Associate Director of CPED and is continuing to work in this capacity.

Debby Zambo, Ed.D., Emerita

Phone: 623-695-0682

Email: debby.zambo@cpedinitiatice.org 